\title{
Full- and Local-Field Strain Evolution and Fracture Behavior of Precracked Granite under Coupled Static and Dynamic Loads
}

\author{
Diyuan Li (D), Feihong Gao, Zhenyu Han, and Quanqi Zhu \\ School of Resources and Safety Engineering, Central South University, Changsha, Hunan 410083, China \\ Correspondence should be addressed to Diyuan Li; diyuan.li@csu.edu.cn
}

Received 22 May 2020; Revised 11 July 2020; Accepted 28 July 2020; Published 12 August 2020

Academic Editor: Yuri S. Karinski

Copyright (c) 2020 Diyuan Li et al. This is an open access article distributed under the Creative Commons Attribution License, which permits unrestricted use, distribution, and reproduction in any medium, provided the original work is properly cited.

\begin{abstract}
Flaws and discontinuities play a crucial role in the failure process of rocks. To investigate the fracturing mechanism of rock with combined flaws composed of crack and hole, the digital image correlation (DIC) method is used to record and analyze the rock failure behavior. Coupled static and dynamic loads are applied on granite specimens with prefabricated flaws by a modified split Hopkinson pressure bar (SHPB) device. The dynamic mechanical properties of the granite specimens are affected by the flaw inclinations with the loading directions. With the inclination angle increasing, the combined strength and peak strain both decrease first and then increase. Full- and local-field strain evolution of the granite specimens is analyzed in a quantitative way by using DIC technique. The specimens with a flaw angle of $45^{\circ}$ are broken relatively evenly with homogenous small particle sizes. The variation trend of fragment sizes is consistent with that of combined strength and absorption energy of the specimens.
\end{abstract}

\section{Introduction}

The geometry, size, and spatial distribution of flaws incubating within the rock are of particular importance to the mechanical properties of rock [1]. Under the long-term effect of geological action and external force, numerous micro- and macroflaws, such as faults, discontinuities, holes, and microfissures, have grown inside the rock. The existence of these natural weak surfaces and flaws is the most fundamental cause of rock failure. In general, exploring the fracturing mechanism of rock with flaws has been one of the focuses of rock mechanics in recent decades [2, 3].

In engineering practice, rock media exhibit very complex characteristics due to the heterogeneity, nonlinearity, and uncertainty properties [4], and usually contain both cracklike and hole-like flaws. The mechanical properties and fracturing behavior of specimens with one of them have been systematically investigated by using different experimental and numerical methods. It has been concluded that the fracture initiation, propagation, and coalescence behavior of specimens with hole-like flaws are influenced by a multitude of factors, such as hole size [5], hole shape [6,7], number of holes $[8,9]$, and stress conditions $[10,11]$. Meanwhile, those of specimens with crack-like flaws are likewise closely related to the geometry of cracks [12], crack numbers $[13,14]$, and crack size [15].

Generally, rock mass contains massive flaws in irregular arrangements and of different shapes in rock engineering. The crack-hole combined with flaws is also a common type of flaws in rock mass. Yang et al. [16] conducted experiments to investigate the effect of fissure angle on the strength and deformation behavior of sandstone specimens with combined flaws. By using photographic monitoring observation, crack coalescence mechanism (tensile crack, hole collapse, far-field crack, and surface spalling) and nine different crack types for the combined flaws are identified. Liu et al. [17] carried out a number of laboratory tests and numerical simulations based on the particle flow code method to analyze the cracking process and stress field evolution in specimens containing combined flaws. The arrangement of the flaws in their studies is interconnected crack-like and hole-like flaws. Yin et al. [18] conducted experiments and numerical simulations to investigate the cracking characteristics of specimens with the flaws in a noncontact geometry of combination of single hole and an inclined fissure 
underneath. However, most of these tests were usually loaded by static uniaxial compression for those studies aforementioned.

In recent decades, scholars have carried out numerous tests based on the SHPB system, to investigate the mechanism of crack initiation and propagation processes on brittle rock. Under individual dynamic loading, the mechanical properties and crack propagation of rock specimens containing a single flaw with different inclination angles are investigated [19-21]. Under coupled static-dynamic loading, the influence of dynamic strain rate and the axial static stress on dynamic behaviors of rock specimens with a hole or fissures are considered by some researches [22-24], while the study focusing on hole-crack flaws is rather limited. In view of this, further study of the fracturing properties of brittle rock materials containing prefabricated hole-crack flaws under coupled static-dynamic loading is essential.

Conventional sensors such as strain gauges, extensometers, and accelerometers are widely used to monitor the deformation of rock specimens. However, these sensors can only measure the strain at a few discrete locations [25-27], and it is obviously not applicable to obtain the local strain surrounding the flaws and cracks in the specimen. To overcome the limitations of traditional contact measurement technology, the digital image correlation (DIC) method, a typical representative of optical technology, has performed its great advantages [28-30]. Fracture is of great importance for the behavior of rock engineering structures [31-33]. Hence, the crack initiation and fracturing process of specimens with prefabricated flaws have been investigated with different auxiliary experimental means, such as acoustic emission (AE) technology [34], computerized tomography (CT) scanning [35, 36], and 3-D X-ray computed tomography [37]. All those mentioned methods are beneficial to provide inspections for rock failure, especially under static compression tests. However, these methods have limitations in recording the strain-field variation in the dynamic experiment.

Besides, there are also many numerical simulation methods. For example, Li et al. [38] adopt the damage smear method (DSM) to investigate trans-scale progressive rock failure process. Damage evolution and accumulation of representative volume elements (RVEs) are used to reveal the characteristics of macroscopic rock failure. In addition, the finite element method (FEM) [39], discrete element method (DEM) $[9,40]$, rock failure process analysis code (RFPA) [41], and particle flow code (PFC) [8, 42] are also widely used to reveal the failure mechanism of rock. However, to conduct numerical modeling, reliable and reasonable constitutive relationship must be built as the basic information. Besides, the parameter selection and validation of these numerical models also require experimental results. It is a challenge in directly obtaining the fulland local-field response, especially measuring true dynamic response of the specimen or structure. Based on the calculation of the gray matrix of the digital speckle images, the surface strain evolution of a specimen can be extracted by using the DIC technique without the need to develop a numerical model.
In the current work, a modified split Hopkinson pressure bar (SHPB) equipment is used to apply the coupled static and dynamic loads to a rock specimen. Each rock specimen is precracked with crack-hole flaws in a noncontact geometry. Digital image correlation (DIC) apparatus is adopted to record the real-time fracturing process of specimens. The full-field cracking process and strain localization evolution are analyzed. The energy dissipation and rock fragmentation size characteristics are summarized. The main purpose of this paper is to obtain the mechanical properties and the strain evolution of brittle rock containing combined flaws under dynamic loading by using the DIC technique. Evidently, the dynamic rock failure analysis by the DIC method will provide some visual observations and proofs for the studies in rock mechanics, particularly for the rocks with natural or artificial flaws.

\section{Methodology}

2.1. Specimen Preparation. The specimens adopted in the experiment were made of granite with high strength and brittleness, which are extracted from Miluo county of Hunan province in China. To determine the basic mechanical properties of the test granite, cylindrical specimens with dimensions of $\Phi 50 \mathrm{~mm} \times 100 \mathrm{~mm}$ (diameter $\times$ height) were prepared and tested under uniaxial compression. The basic mechanical parameters are listed in Table 1.

Rectangular cuboid specimens (60 $\mathrm{mm}$ in length, $45 \mathrm{~mm}$ in width, and $15 \mathrm{~mm}$ in thickness) were tested under the coupled static and dynamic loads by a modified split Hopkinson pressure bar (SHPB) apparatus. A circular hole ( $10 \mathrm{~mm}$ in diameter) was cut by using a high-pressure water jet apparatus at each specimen center. A contrast group with only circular hole (Group C) and an experimental group with crack unexposed to the hole (Group U) were prepared and tested afterwards. The specific geometrical layout about the test specimen can be seen in Figure 1. The prefabricated combined flaws contain a hole-like flaw and a crack-like flaw $15 \mathrm{~mm}$ in length in different inclination angles $\beta$ (the angle between the crack-like flaws and the loading direction, including $0^{\circ}, 30^{\circ}, 45^{\circ}, 60^{\circ}$, and $90^{\circ}$ ). The artificial crack has a minimum distance $d$ of $7 \mathrm{~mm}$ from the edge of the internal hole, and the layout is displayed in Figure 2. The prefabricated crack is always tangent to a circle with a radius of $12 \mathrm{~mm}(R=d+r)$. Tangent point, which is also the midpoint of the crack, rotates counterclockwise in the second quadrant. The angles aimed to investigate in this paper are limited in only one quadrant, and larger angles are not discussed due to symmetry.

Moreover, the dimensions and mechanical parameters of each type of specimens are listed in Table 2. It is noteworthy that the specimen no. in Table 2 describes the number of crack, crack inclination angle, and the specimen number (three specimens are prepared for each type). For example, U-30-2 refers to the second specimen (no. 2) containing a single crack with $\beta=30^{\circ}$.

Before the tests, artificial speckle patterns should be prepared on the specimen surface. At first, a layer of white paint was sprayed thinly and evenly on the surface of 
TABLE 1: Mechanical parameters of tested granite specimens.

\begin{tabular}{lc}
\hline Properties & Values \\
\hline Young's modulus & $47.01 \mathrm{GPa}$ \\
Poisson's ratio & 0.28 \\
Compressive strength & $125.87 \mathrm{MPa}$ \\
Tensile strength & $6.7 \mathrm{MPa}$ \\
Longitudinal wave velocity & $3692.9 \mathrm{~m} / \mathrm{s}$ \\
Density & $2666.7 \mathrm{~kg} / \mathrm{m}^{3}$ \\
\hline
\end{tabular}

specimens. If the paint is too thick, the crack initiation and propagation of the specimens are difficult to be reflected on the surface in time, which would result in the inaccurate acquisition of images captured by the high-speed digital camera (Phantom V711, produced by Vision Research Inc.). After the paint was dry, speckles were coated manually and randomly, and each speckle was set to cover approximately 4-6 pixels. It is noteworthy that a speckle particle size is the same as the distance between two adjacent speckles to ensure that it can be caught and optimized by computer simulation.

\subsection{Testing Equipment}

2.2.1. Loading System. Rectangular cuboid granite specimens were tested by using a modified split Hopkinson pressure bar (SHPB) system with coupled static and dynamic loads, as shown in Figure 1. The modified SHPB system consists of a gas gun, a cone-shaped striker, an incident bar, a transmitted bar, a momentum bar, a damper, and a set of axial static pressure device [44]. The basic parameters of elastic bars in SHPB device are shown in Table 3.

2.2.2. Digital Image Correlation (DIC) System. During the test, DIC apparatus is used to monitor the deformation evolution of the specimens and it mainly consists of the high-speed digital camera and software system. The installation of this apparatus is shown in Figure 3. A gooseneck lamp was installed perpendicularly to the specimen to provide illumination. Once triggered, all images were capture and simultaneously stored in a computer for the subsequent processing.

The length-pixel ratio of the imaging system is $0.234 \mathrm{~mm} /$ pixel. The frame rate of the high-speed camera is set to $79161 \mathrm{fps}$ (frames per second) with a resolution of $256 \times 256$ pixels so that it can capture an image each $12.63 \mu$ s. After impact tests, the captured speckle images are analyzed by two-dimensional visual image correlation (VIC-2D) software from Correlated Solutions, Inc. (CSI). (Please refer to reference [46] for more details about the software). Generally, VIC-2D is advantageous for monitoring in-plane deformation and strain measurements of any planar surface on account of its simple setup. However, there are some limitations for the DIC system: (a) measurement accuracy mostly depends on the quality of speckle particle. (b) Measurements are limited to in-plane surface deformation and strain. (c) Once the strain is less than $100 \mu \varepsilon$, DIC is not recommended for any applications [47].
2.3. SHPB Test. The main loading stages of the test are as follows. First, static loads of $20 \mathrm{MPa}$ were applied manually on the specimen in a slow and uniform speed by the axial static pressure loading device, and the static loading rate is $0.17 \mathrm{MPa} / \mathrm{s}$. Second, dynamic impact loads were applied to the granite specimen by launching the cone-shaped striker in the SHPB system. The dynamic strain rate is in the range of $50 \sim 60 \mathrm{~s}^{-1}$. In the test, once a transistor-logic (TTL) signal was generated by the strain gauge attached on the incident bar, the high-speed camera and the oscilloscope were both triggered simultaneously.

\section{Testing Results and Analysis}

3.1. Testing Validity. During the test, a slowly rising half sine wave is generated by launching the cone-shaped striker to impact the incident bar. When the incident wave propagates to the bar-specimen interface, a part of the wave is reflected (reflected wave), and the remainder passes through the specimen and is transmitted into the transmitted bar (the transmitted wave). Hence, stress equilibrium at the two ends of the specimen should be achieved in the test to ensure that results are convinced and reasonable. It means before the rock specimen reaches failure, the transmitted stress wave is almost equal to the superposition of the incident wave and reflected wave.

Taking specimen U-0-3 as an example, the stress waves of the specimen are shown in Figure 4. The transmitted stress wave (Tra) and the superposition of incident wave and reflected wave $(\mathrm{Inc}+\mathrm{Re})$ in the middle part almost coincide with each other, indicating that the stress equilibrium of the specimen is satisfied during the dynamic test.

3.2. Dynamic Stress-Strain Curve. The time when impact stress wave propagates to the specimen end is set as the starting point in the test. Figure 5 shows the dynamic stressstrain curves of the granite specimens with prefabricated flaws. It can be approximately classified into three typical stages: (I) linear elastic deformation stage, (II) nonlinear deformation stage, and (III) macroscopic failure stage.

Evidently, the compaction stage which should be concave upward cannot be observed in this curve. Because the initial compaction of microfissures in the interior of rock specimens has achieved in prestatic loading, the curve goes directly to the stage of linear elasticity. The first stage has a quite short duration. With further loading, the stress-strain curve exhibits nonlinear property. New crack initiation and propagation occur in this stage.

When reaching the peak stress, the stress-strain curve shows a downward trend, which may result from the propagation of macrofractures. Hence, the postpeak stage is defined as macroscopic failure stage. In this stage, macroscopic fractures form and propagate to the specimen ends, finally causing the brittle failure.

3.3. Mechanical Properties. According to the one-wave propagation theory in the SHPB test, the axial stress $\sigma_{(t)}$, strain $\varepsilon_{(t)}$, and strain rate $\varepsilon_{(t)}$ can be derived by the following equations [48]: 


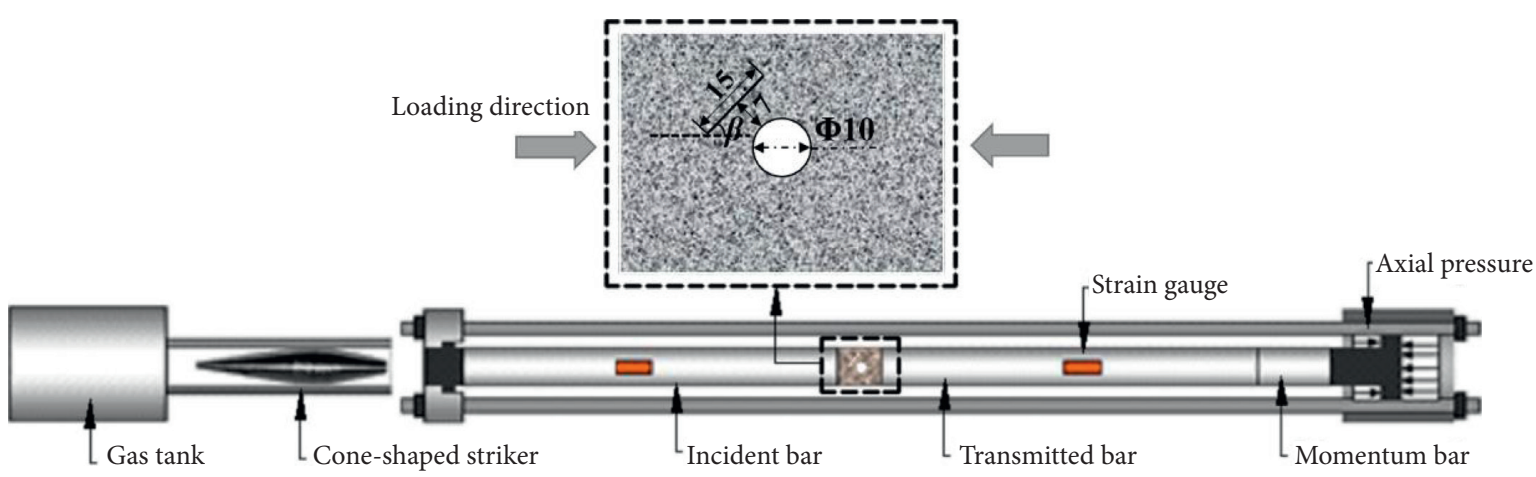

Figure 1: SHPB system modified from reference [43] for coupled axial static and dynamic loading and the geometry of the specimen.

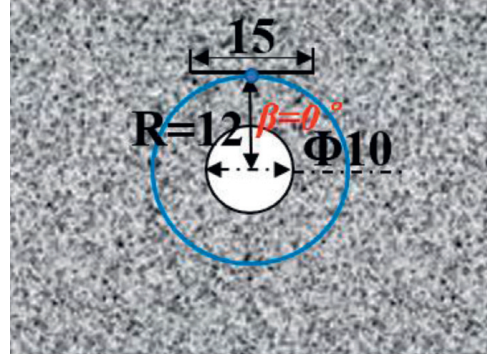

(a)

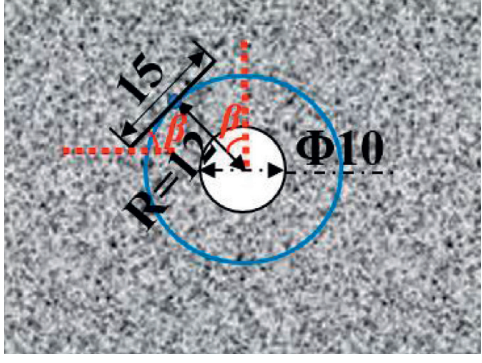

(b)

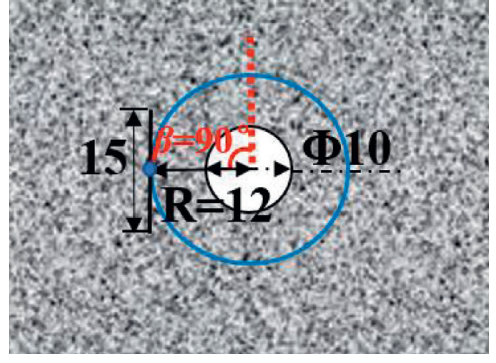

(c)

Figure 2: The layout of the combined flaws composed of crack and hole.

TABLE 2: Geometric dimensions and mechanical parameters of granite specimens.

\begin{tabular}{|c|c|c|c|c|c|c|c|c|}
\hline Specimen no. & Length $(\mathrm{mm})$ & Height (mm) & Thickness (mm) & $\sigma_{\mathrm{as}}(\mathrm{MPa})$ & $\sigma_{\mathrm{d}}(\mathrm{MPa})$ & $\sigma_{\mathrm{cs}}(\mathrm{MPa})$ & Peak strain $\left(10^{-3}\right)$ & Strain rate $\left(\mathrm{s}^{-1}\right)$ \\
\hline C-0 & 60.28 & 45.44 & 15.16 & 20 & 170.31 & 190.31 & 3.20 & 56.29 \\
\hline $\mathrm{U}-0-1$ & 60.47 & 45.28 & 15.41 & 20 & 173.34 & 193.34 & 2.82 & 50.08 \\
\hline $\mathrm{U}-0-2$ & 60.55 & 44.62 & 15.40 & 20 & 168.57 & 188.57 & - & 53.58 \\
\hline $\mathrm{U}-0-3$ & 60.51 & 45.35 & 15.17 & 20 & 165.25 & 185.25 & 2.66 & 55.95 \\
\hline U-30-1 & 60.4 & 45.45 & 15.40 & 20 & 112.10 & 132.1 & 1.98 & 58.19 \\
\hline U-30-2 & 60.14 & 44.53 & 15.50 & 20 & 125.69 & 145.69 & 1.17 & 53.36 \\
\hline U-30-3 & 60.16 & 44.54 & 15.44 & 20 & 133.84 & 153.84 & 1.49 & 59.32 \\
\hline U-45-1 & 59.89 & 45.28 & 14.02 & 20 & 110.02 & 130.02 & 1.75 & 57.23 \\
\hline U-45-2 & 60.23 & 44.49 & 15.43 & 20 & 106.97 & 126.97 & 1.80 & 59.43 \\
\hline U-45-3 & 60.15 & 45.40 & 15.54 & 20 & 118.14 & 138.14 & 1.78 & 55.13 \\
\hline U-60-1 & 60.13 & 45.08 & 13.93 & 20 & - & - & - & - \\
\hline U-60-2 & 60.10 & 45.11 & 15.50 & 20 & 123.50 & 143.50 & 1.91 & 55.43 \\
\hline U-60-3 & 60.11 & 45.10 & 15.47 & 20 & 121.33 & 141.33 & 2.10 & 62.10 \\
\hline U-90-1 & 60.35 & 45.24 & 15.61 & 20 & 133.54 & 153.54 & 2.17 & 47.24 \\
\hline U-90-2 & 60.46 & 45.45 & 14.15 & 20 & - & - & - & - \\
\hline U-90-3 & 60.54 & 45.24 & 15.46 & 20 & 138.77 & 158.77 & 1.90 & 57.44 \\
\hline
\end{tabular}

Note: $\sigma_{\mathrm{as}}$ is the axial static pressure, $\sigma_{\mathrm{d}}$ is the dynamic strength, and $\sigma_{\mathrm{cs}}$ is the combined strength. The symbol "-" indicates that the data are eliminated for the specimen owing to large deviation.

TABLE 3: Basic parameters of the elastic bars.

\begin{tabular}{lc}
\hline Properties & Values \\
\hline Material & $40 \mathrm{Cr}$ alloy steel \\
Diameter & $50 \mathrm{~mm}$ \\
Elastic modulus & $233 \mathrm{GPa}$ \\
$P$-wave velocity & $5400 \mathrm{~m} / \mathrm{s}$ \\
Density & $7817 \mathrm{~kg} / \mathrm{m}^{3}$ \\
\hline
\end{tabular}

$$
\begin{aligned}
\sigma_{(t)} & =\frac{A_{e} E_{e}}{2 A_{s}}\left[\varepsilon_{I}(t)+\varepsilon_{R}(t)+\varepsilon_{T}(t)\right], \\
\varepsilon_{(t)} & =\frac{C_{e}}{L_{s}} \int_{0}^{t}\left[\varepsilon_{I}(t)-\varepsilon_{R}(t)-\varepsilon_{T}(t)\right] \mathrm{d} t, \\
\dot{\varepsilon}_{(t)} & =\frac{C_{e}}{L_{s}}\left[\varepsilon_{I}(t)-\varepsilon_{R}(t)-\varepsilon_{T}(t)\right],
\end{aligned}
$$




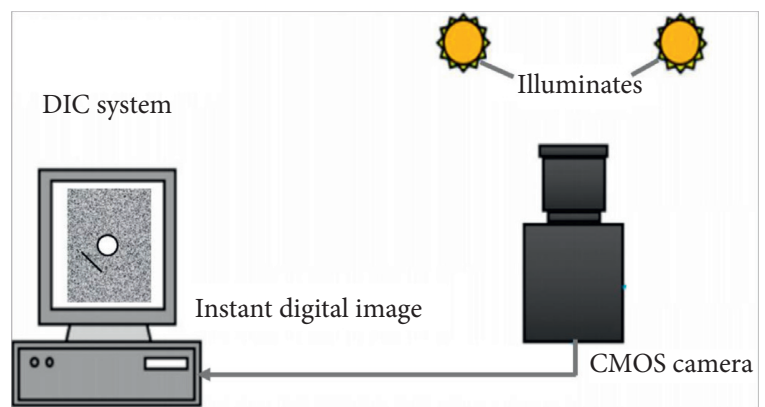

FIgURE 3: Schematic diagram of the DIC system in the tests modified from reference [45].

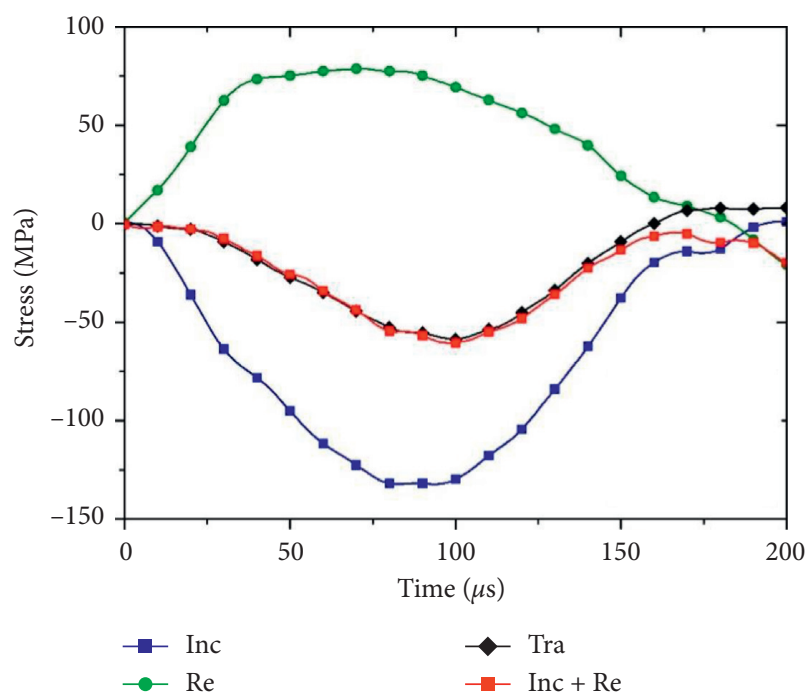

FIgURE 4: Typical stress equilibrium relationship of specimen U-0-3.

where $A_{e}, E_{e}$, and $C_{e}$ are the cross-sectional area, Young's modulus, and $P$-wave velocity of the elastic bar, respectively. $A_{s}$ and $L_{s}$ are the cross-sectional area and length of the specimen, respectively. $\varepsilon_{I}, \varepsilon_{R}$, and $\varepsilon_{T}$ are the incident, reflected, and transmitted strain pulses, respectively.

Thus, the dynamic mechanical properties of the granite specimens can be obtained. The results are listed in Table 2. The strain rate $\varepsilon_{(t)}$ of the specimens is maintained at about $50-60 \mathrm{~S}^{-1}$, which can be regarded as a constant strain rate range. Dynamic strength $\sigma_{d}$ reflects the impact resistance of the specimen, and the peak strain $\varepsilon_{(t)}$ refers to the strain corresponding to the dynamic strength. Moreover, the combined strength $\sigma_{\mathrm{cs}}$ is the sum of the prestatic pressure and the dynamic strength, which reflects the actual bearing capacity of the specimens [44]. The average value and the standard deviation of the testing results are provided in Figure 6.

The existence of artificial flaws are responsible for strength weakening [49]. Combined strength and peak strain of the specimens in Group $U$ both decrease first and then increase with the inclination angle increasing gradually. The strength reduction of specimens with an artificial crack-like flaw of $0^{\circ}$ is only $0.66 \%$ lower than that of specimen C- 0 ,

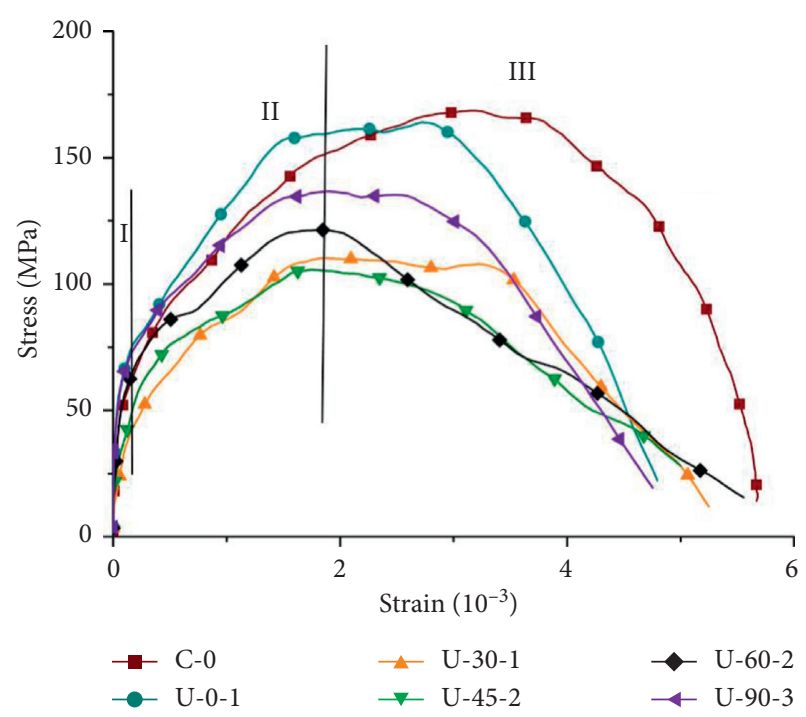

Figure 5: Dynamic stress-strain curves of precracked specimens.

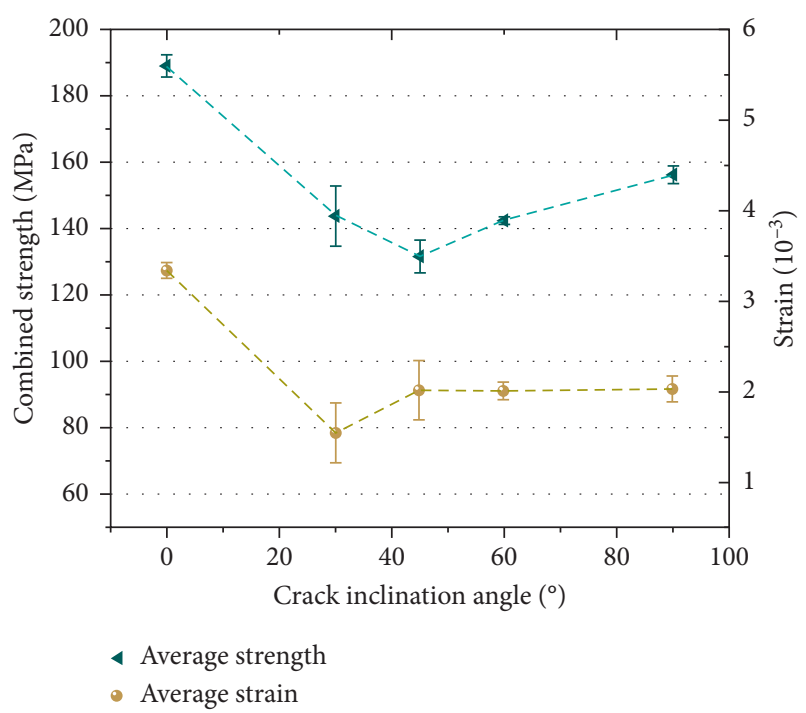

FIGURE 6: The relationship between combined strength/peak strain and the flaw inclination angles.

while the strength reduction of specimens with a prefabricated flaw of $30^{\circ}, 45^{\circ}, 60^{\circ}$, and $90^{\circ}$ is $24.40 \%, 30.79 \%$, $25.17 \%$, and $16.57 \%$, respectively. The peak strain of specimen C- 0 is $0.32 \%$, whereas it ranges between $0.177 \%$ and $0.204 \%$ for the specimens with combined flaws, which has a significant reduction.

3.4. Fracturing Process. During the past few decades, white patches are regarded as a precursor to observe new cracks in many studies [50]. Moreover, the initiation, extension, and coalescence of fractures are described in a qualitative way. In this study, based on DIC technique, the major principal strain contours of the specimen are obtained during the coupled static-dynamic loading, as shown in Table 4. It can reflect the evolution of the surface strain field in the process of loading intuitively and quantitatively. 
TABLE 4: The major principal strain contours of typical specimens during the test.

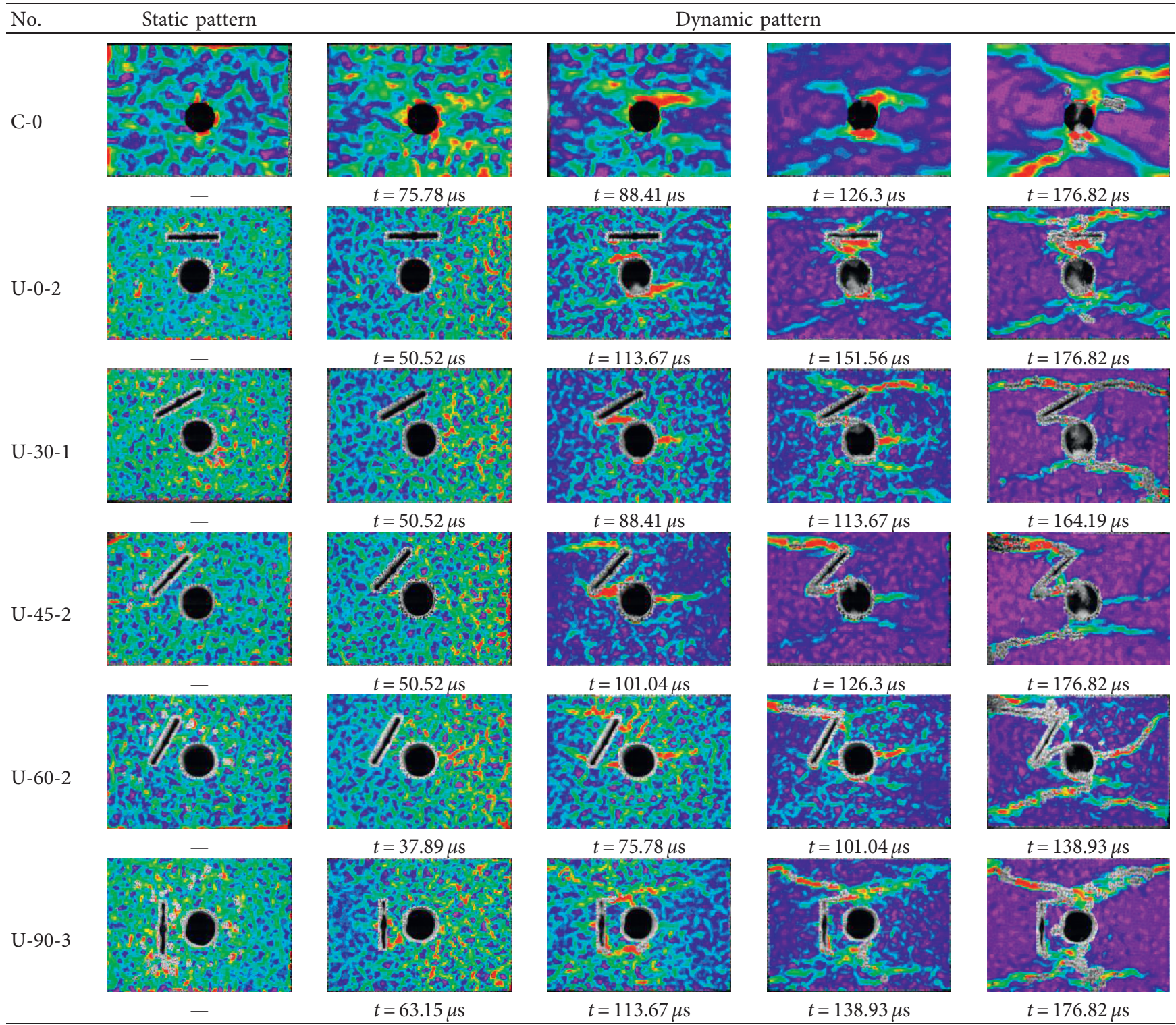

In the evolution of strain field, different types of specimen behave quite differently. It demonstrates the geometries of combined flaws significantly affect the deformation characteristics [18], which are summarized as follows:

(1) In static loading pattern, the whole specimen is in the state of compression. However, some local high strains can be observed prior to observable cracks, which usually occur around the combined flaws. These local high strains are similar to the white patches mentioned earlier [51], which could establish foundation to reveal the new fracture trajectories and initiation mechanisms in the subsequent dynamic loading.

(2) In dynamic loading patterns, at early stage of dynamic loading, the high strain shows obvious migration characteristics with the propagation direction of the stress wave (specimen C-0 is not involved). The incident wave enters from the barspecimen interface, and soon afterwards high strain concentrations are formed in the right half of specimens. Next, they move forward along the propagation of the stress wave and then gradually distribute near the combined flaws of the specimens. With further loading, the high strain zones are widened and propagated, accompanied with some secondary cracks.

(3) Two types of fractures are commonly observed: tensile fractures and shear fractures. Tensile fracture is nearly parallel to the loading direction, while shear fracture is oblique with respect to the loading direction [52-54]. The tensile fractures mostly occur at the flaw tip, while a few of them occur at the side wall of the circular hole. Shear fractures which formed at the top and bottom of the hole extend along the 


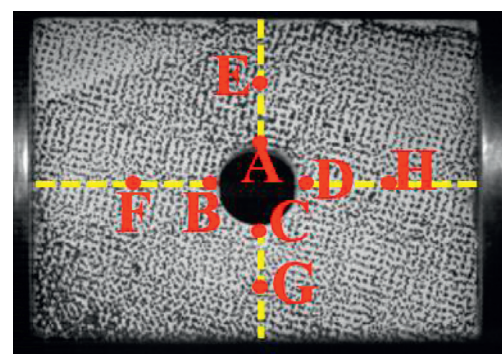

(a)

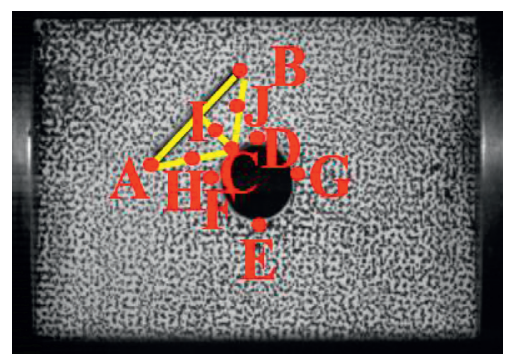

(d)

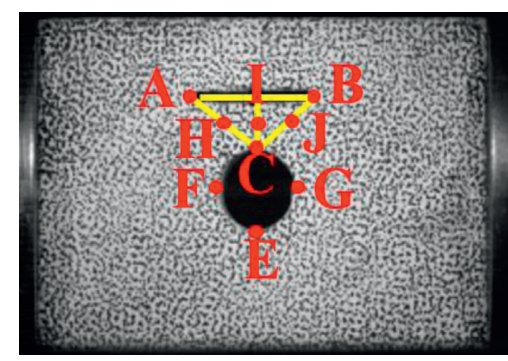

(b)

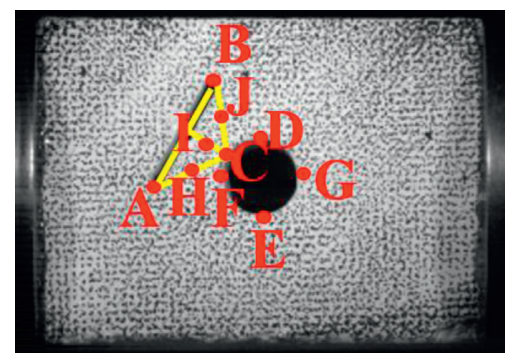

(e)

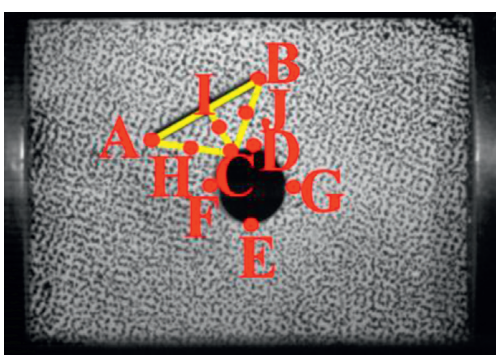

(c)

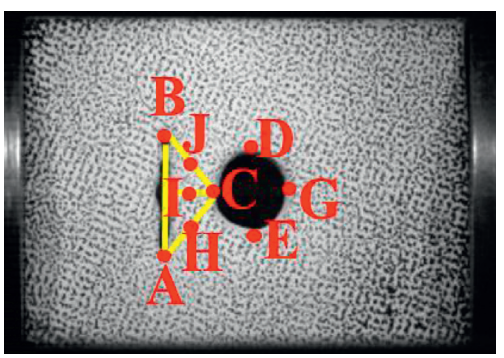

(f)

Figure 7: The measurement points of specimens: (a) with no artificial crack and (b)-(f) with artificial crack of angles $0^{\circ}, 30^{\circ}, 45^{\circ}, 60^{\circ}$, and $90^{\circ}$, respectively.

diagonal directions at an angle with the loading direction, generating an $X$ or a half $X$-shaped fracture, which dominate the rock failure process during the dynamic loading.

(4) Fractures emanating from the top or bottom of the hole coalesce with those initiating from crack tips. The crack tip which is near with the internal hole has the precedence. The coalescence modes of five types of flaw geometry will be discussed in Section 4.1 in detail.

3.5. Strain Evolution Analysis of the Measurement Points. In this paper, in order to obtain the strain localization evolution processes, some key measurement points are selected at discrete locations on the specimen surface, as shown in Figure 7. DIC technology is used to extract the strain data during the failure process, and then strain analysis and comparison about these points are conducted. In specimen $\mathrm{C}-0, A, B, C$, and $D$ are, respectively, located at the top, left side, bottom, and right side of the hole. $E, F, G$, and $H$ are, respectively, located at the midpoints of the four lines from measurement points $A, B, C$, and $D$ to the edges of the specimen. In the specimens of U-0, U-30, U-45, U-60, and $\mathrm{U}-90, A$ and $B$ are, respectively, the left and right tips of the crack; $C$ is the triangular vertex with line $A B$ as the base; $D$ and $E$ are the top and bottom of the hole; $F$ and $G$ are the left and right wall of the hole; $H, I$, and $J$ are equidistant on the median of the triangle. Taking typical specimens as examples from six groups, the strain-time curves of measurement points are plotted in Table 5, including the maximum principal strain $e 1$ and the minimum principal strain $e 2$.
For specimen C-0, it can be seen from Table 5(a) that when $t=88 \mu \mathrm{s}$, the peak strength is $170.3 \mathrm{MPa}$, and the local strain of all measurement points is in a low fluctuation. After that, the maximum principal strain at the top and bottom of the hole begins to increase significantly, and tensile cracks appear along the loading direction (Table 4). The strain-time (e2) curve in Table 5(b) shows that there are shear fractures perpendicular to the loading direction appearing firstly at the top and bottom of the hole $(A, C)$, and then they are restrained gradually. At $t=200 \mu \mathrm{s}$, the value of $e 2$ drops sharply to a small value but later on increases again. At this moment, the specimen is completely destroyed, and shear fractures dominate the failure process.

For the specimens with prefabricated cracks, the statistic results are summarized in Table 6 , and the variation rules are summarized as follows:

(1) The initiation of new fractures mainly occurs at crack tips $(A, B)$, and the top and bottom of holes $(D, E)$. However, the strain of $C$ has an obvious rise only at the inclination angle of $0^{\circ}, 30^{\circ}$, and $45^{\circ}$. That is mainly because point $C$ is in a quite close position to point $D$ (hole top) at those angles. The strain of $F, G, H, I$, and $J$ is in low fluctuation.

(2) The $e 2$ value at point $A$ increases significantly, while the $e 1$ value increases in a relatively low level. The $e 1$ value of point $B$ increases rapidly, while the fluctuation of $e 2$ value is weak. It illustrates that shear stress is mainly concentrated at the left crack tip $(A)$, while tensile stress is mainly concentrated at the right crack tip $(B)$. At the angle of $90^{\circ}$, the strain at the top and bottom of the hole is significantly higher than that at the two tips of the crack. For this condition, new cracks are more easily occurred around the hole 
TABle 5: Strain-time evolution curves of the measurement points in typical specimens.
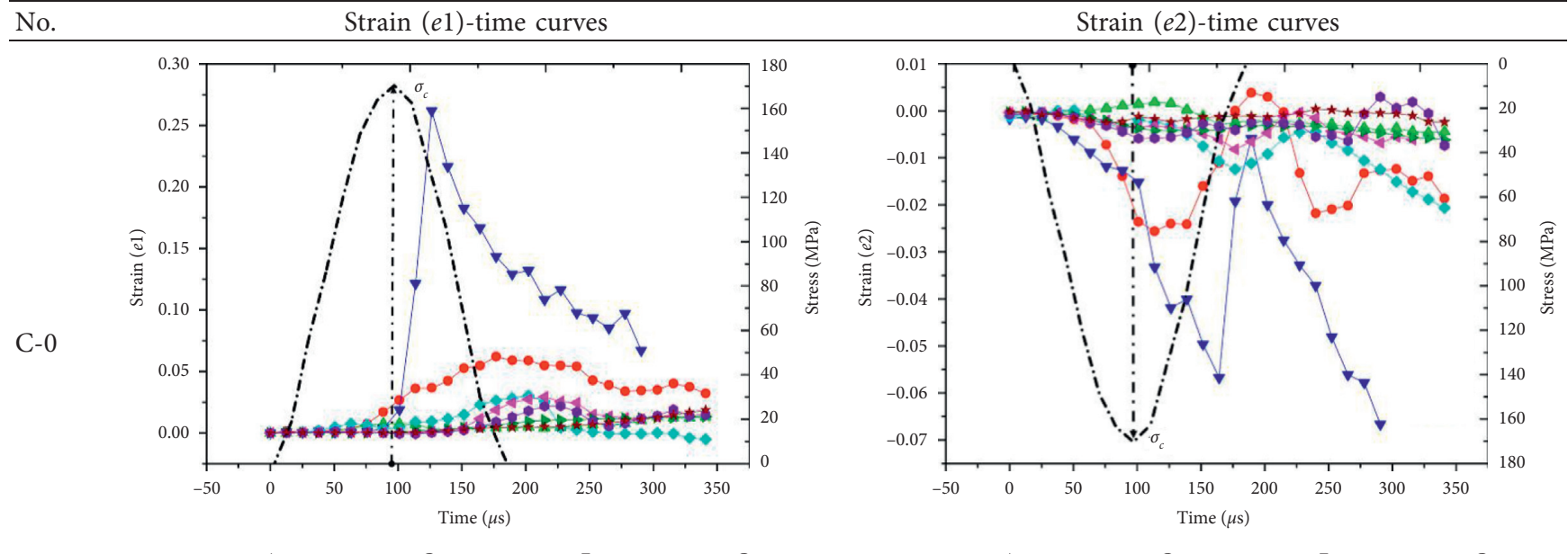

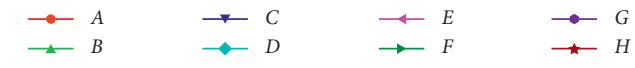

(a)
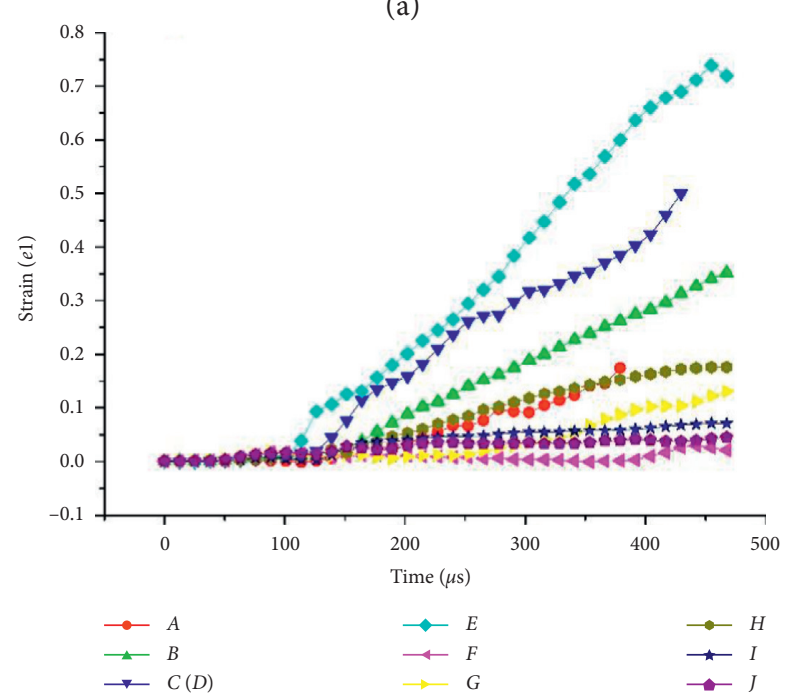

(c)

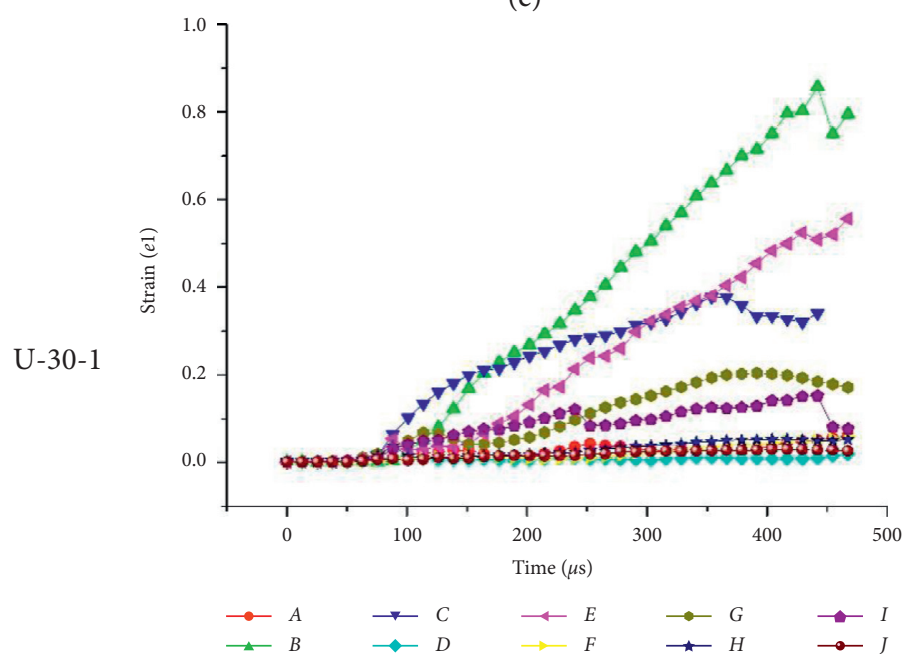

(e)

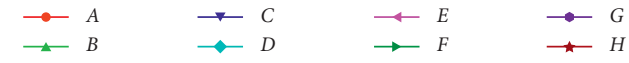

(b)

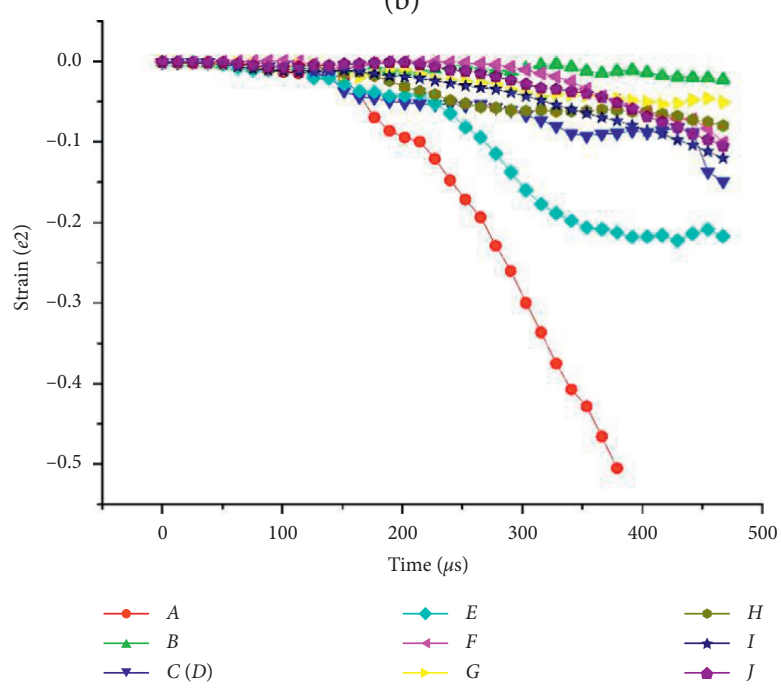

(d)

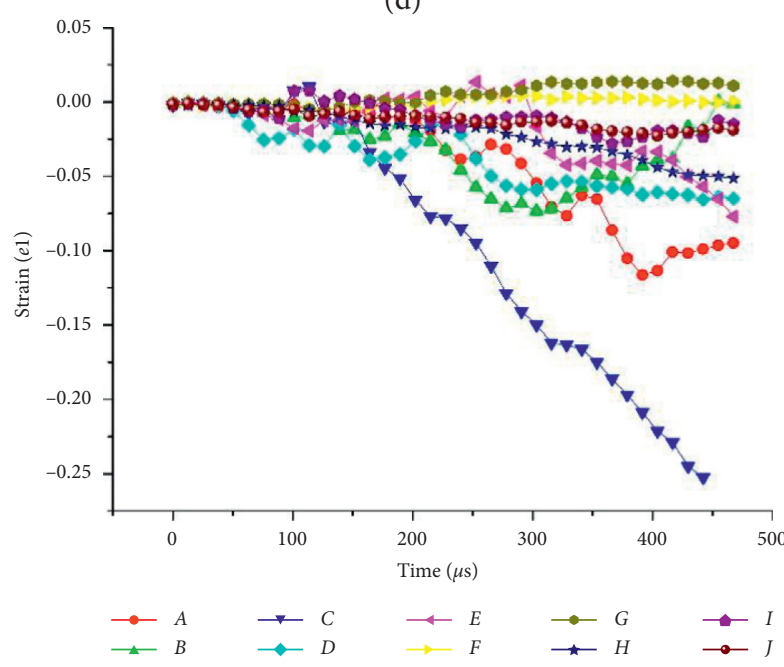

(f) 
TABle 5: Continued.

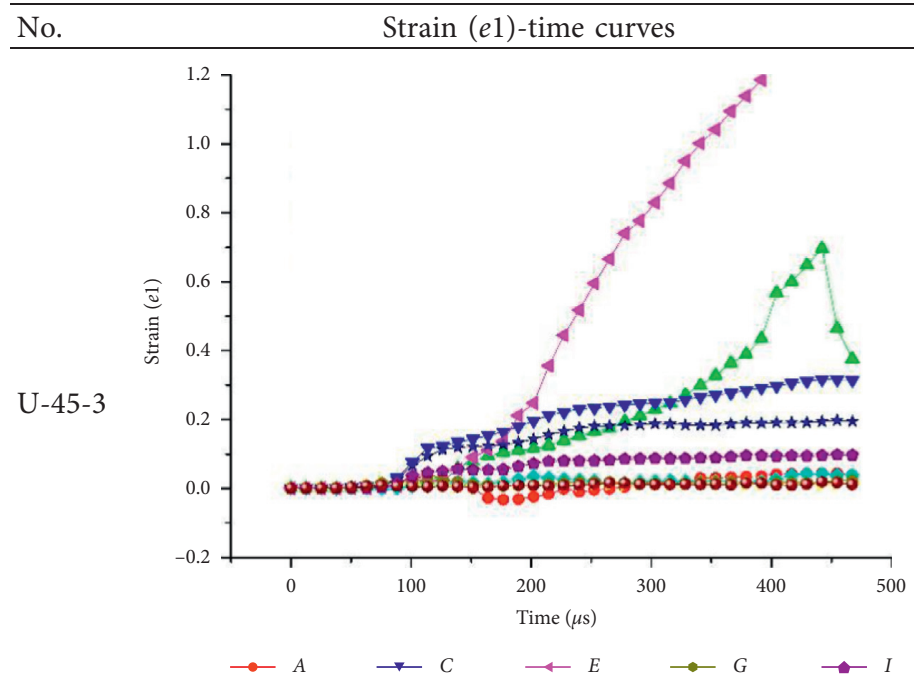

(g)

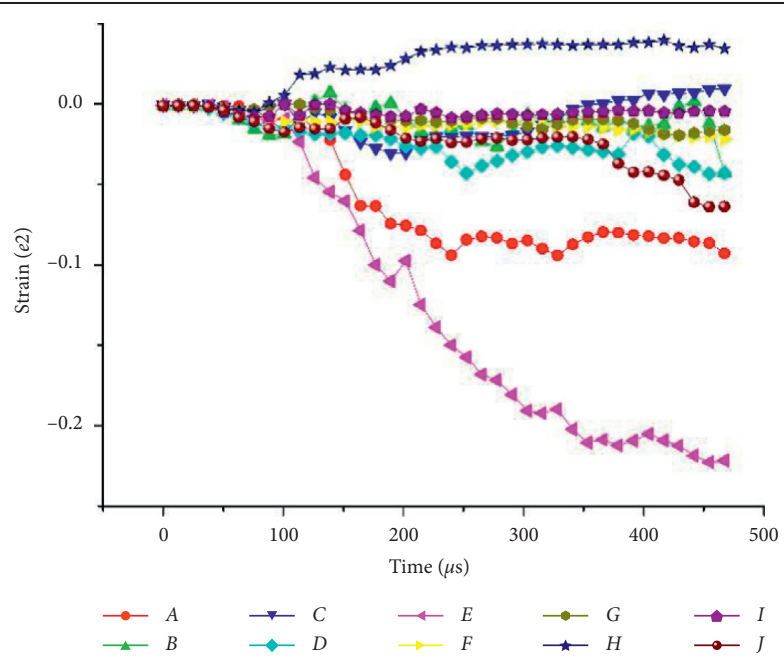

(h)

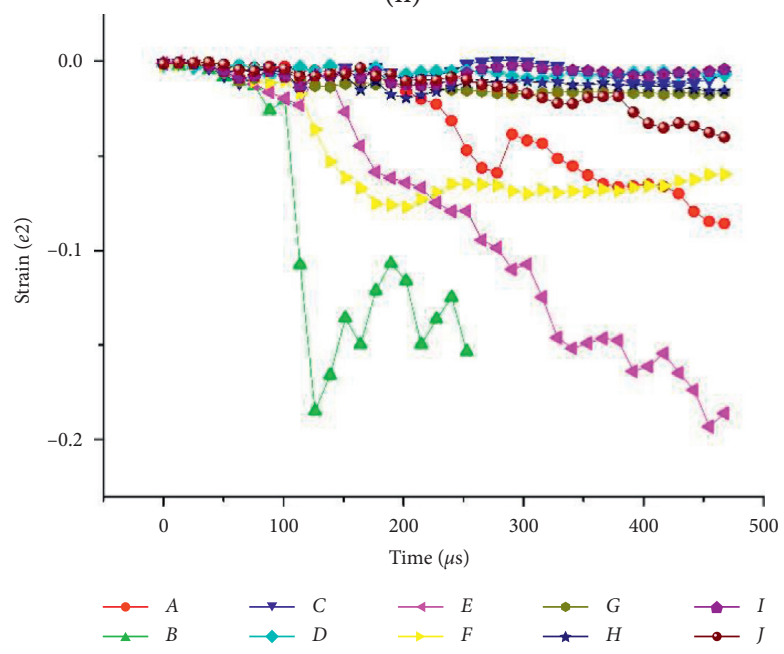

(j)

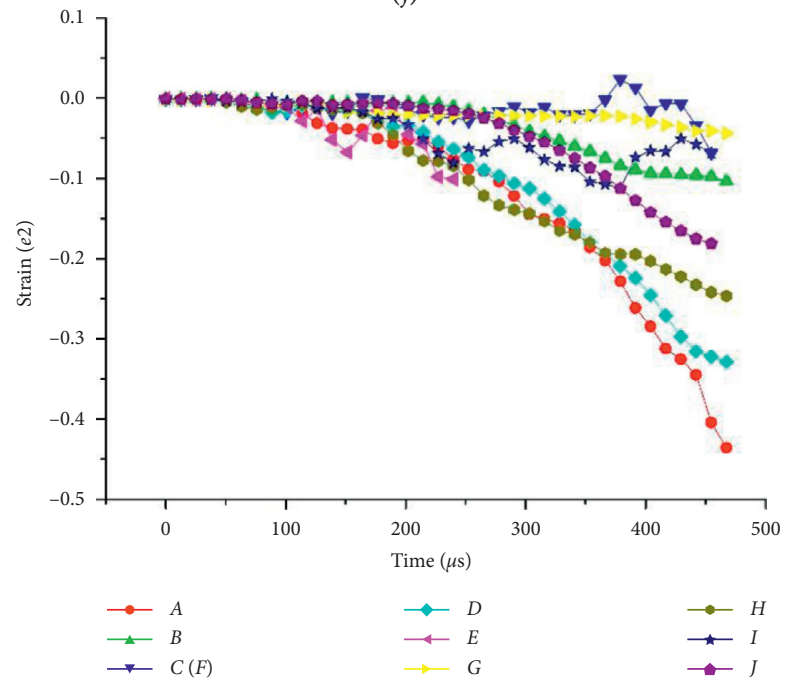

(1) 
TABLE 6: Statistical table of strain characteristics of all measurement points in each group.

\begin{tabular}{lcccccccccc}
\hline \multirow{2}{*}{ Angle } & & \multicolumn{10}{c}{ Measurement points } \\
& $A$ & $B$ & $C$ & $D$ & $E$ & $F$ & $G$ & $H$ & $I$ & $J$ \\
\hline $0^{\circ}$ & $e 2$ & $e 1$ & $e 1$ & $e 1, e 2$ & $e 1, e 2$ & - & - & $e 1$ & - & - \\
$30^{\circ}$ & $e 2$ & $e 1$ & $e 1, e 2$ & - & $e 1, e 2$ & - & - & - & - & - \\
$45^{\circ}$ & $e 2$ & $e 1$ & $e 1$ & - & $e 1, e 2$ & - & - & $e 1$ & - & - \\
$60^{\circ}$ & $e 2$ & $e 1, e 2$ & - & - & $e 1, e 2$ & - & - & - & - & - \\
$90^{\circ}$ & $e 1, e 2$ & $e 1, e 2$ & - & $e 1, e 2$ & $e 1, e 2$ & - & - & $e 2$ & - & $e 2$ \\
\hline
\end{tabular}

Note: " $e 1, e 2$ " denotes an obvious rise process as shown in its strain-time curves. The symbol "-_" denotes a relatively low fluctuation of the straintime curves, generally less than 0.2 .

rather than at the crack tips. As the circular hole is completely located in front of crack and exposed to the stress wave earlier and larger than the preset crack. Therefore, the roof and floor of the internal hole could become the preferable location for microcracks to gather and develop, rather than at the tip of the crack.

(3) The $e 1$ and $e 2$ values of point $D$ (hole top) increase significantly at the angles of $0^{\circ}$ and $90^{\circ}$, while those two values are relatively low at the angles of $30^{\circ}, 45^{\circ}$, and $60^{\circ}$. The $e 1$ and $e 2$ values of $E$ (hole bottom) are both large in the angle range of $0^{\circ} \sim 90^{\circ}$. When these specimens are impacted to fail, the inverted V-shaped fractures appear at the bottom of the hole.

\section{Discussion}

4.1. Crack Coalescence Modes. Figure 8 shows the crack coalescence modes of precracked specimens with different flaw inclination angles. There are three types of crack coalescence modes in the present study: regional failure (Figure 8(a)), monotype fracture (Figures $8(\mathrm{c})-8(\mathrm{~d})$ ), and mixed mode fractures (Figures $8(\mathrm{~b})-8(\mathrm{e})$ ). The detailed coalescence categories are described as follows:

(i) Regional failure: from Figure 8(a), fractures derived from the bottom of horizontal crack are all connected with the fissures initiating from crown area of the circular hole. Then, the damage zone is formed as an inverted triangle, and the damage intensity in this area is relatively high.

(ii) Monotype fracture: in Figures 8(c) and 8(d), a shear fracture of long and narrow shape is formed and it connects the lower crack tip and the crown area of hole.

(iii) Mixed mode fractures: in Figure 8(b), the tensile fracture derived from the lower tip of crack is connected with the shear fracture above the hole. Furthermore, in Figure 8(e), tensile fractures generated at both tips of crack coalesce with the shear fractures emerged at the top and bottom of the hole, respectively, forming a symmetrical failure.

It can be seen that tensile fractures are usually occurred from the crack tip, while shear fractures are often formed at the boundary of circular hole. However, this phenomenon is not applicable in the situation that the crack tip is relatively close to the hole. In this condition, the microfissures which initiate from the crack tip and crown area of the hole propagate toward each other rapidly, and then a visible fracture is formed afterwards (Figures $8(\mathrm{c})$ and $8(\mathrm{~d})$ ).

4.2. Average Strain Evolution of Failure Zone. Based on the above analysis about the crack coalescence modes between the combined flaws, the main failure zones which involve combined flaws are selected to analyze the average strain in specimens. As shown in Figure 9, taking the specimen with a flaw angle of $45^{\circ}$ as an example, a circle with the center of point $\mathrm{C}$ and a radius of $12 \mathrm{~mm}$ is delineated. The average strain (only $e 1$ is analyzed) of the area is calculated by DIC technique, and the strain-time curves of five typical specimens are plotted in Figure 10.

It can be seen from Figure 10 that the average strain of the failure zone in specimen U-90-3 (symmetrical mixed fractures along the loading direction) is most prominent. Then, specimen U-0-3 (regional failure) follows. In specimens U-30-1, U-45-3, and U-60-1, there is a dominant fracture connecting the prefabricated crack with the hole. The order of the average strain within the three failure zones is $45^{\circ}>30^{\circ}>60^{\circ}$. The characteristics of this trend are consistent with the crack coalescence modes in Figure 8.

4.3. Energy Characteristics. Rock failure is actually a process of energy dissipation. The specimens applied prestatic loading are in the compressive state with considerable elastic energy accumulated. Once it is subjected to sufficiently large dynamic disturbances, the stored elastic energy is rapidly released and may result in severe damage. Therefore, it is of great importance to analyze the law of energy consumption. Based on the one-dimensional stress wave theory and data recorded in the SHPB tests, the average value of incident energy $E_{I}$, the reflected energy $E_{R}$, the transmitted energy $E_{T}$, and the absorption energy $\mathrm{E}_{\mathrm{A}}$ can be calculated [48] by the following equations. The results are listed in Table 7:

$$
\begin{aligned}
& E_{\mathrm{I}}=\frac{A_{e}}{\rho_{e} C_{e}} \int_{0}^{\tau} \sigma_{I}^{2}(t) \mathrm{d} t, \\
& E_{\mathrm{R}}=\frac{A_{e}}{\rho_{e} C_{e}} \int_{0}^{\tau} \sigma_{R}^{2}(t) \mathrm{d} t, \\
& E_{\mathrm{T}}=\frac{A_{e}}{\rho_{e} C_{e}} \int_{0}^{\tau} \sigma_{T}^{2}(t) \mathrm{d} t, \\
& E_{\mathrm{A}}=E_{\mathrm{I}}-E_{\mathrm{R}}-E_{\mathrm{T}},
\end{aligned}
$$

where $\sigma_{\mathrm{I}}(t), \sigma_{\mathrm{R}}(t)$, and $\sigma_{\mathrm{T}}(t)$ are the incident, reflected, and transmitted stress at time $t$, respectively, and $\rho_{e} C_{e}$ is the wave impedance of the bars.

At different flaw inclination angles, the incident energy $E_{\mathrm{I}}$, the reflected energy $E_{\mathrm{R}}$, the transmitted energy $E_{\mathrm{T}}$, and the absorption energy $E_{\mathrm{A}}$ of the granite specimens have different values. Particularly, $E_{\mathrm{A}}$ is the energy absorbed by 


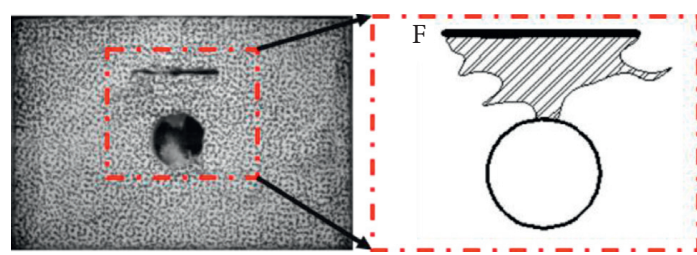

(a)

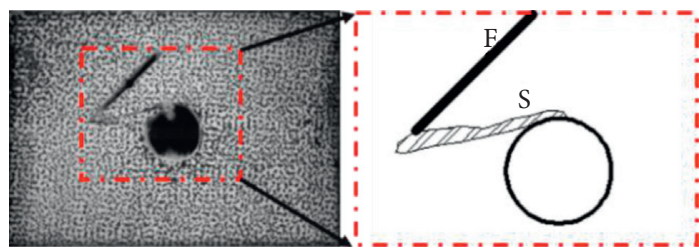

(c)

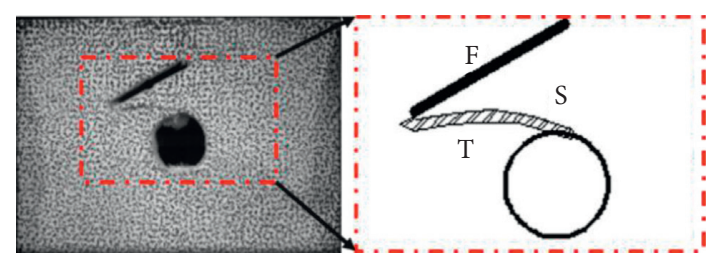

(b)

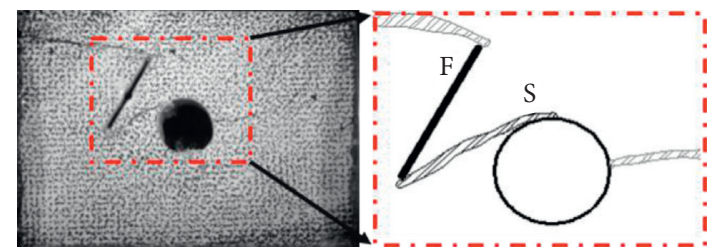

(d)

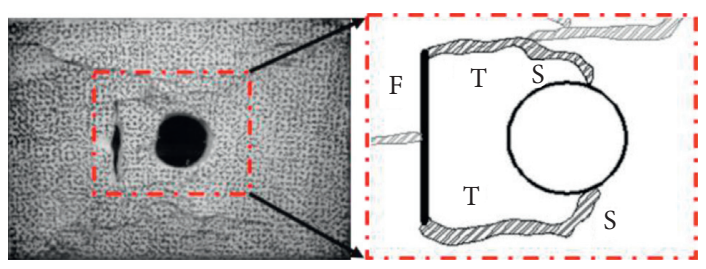

(e)

FiguRE 8: Crack coalescence modes of precracked specimens with different flaw inclination angles of (a) $0^{\circ}$, (b) $30^{\circ}$, (c) $45^{\circ}$, (d) $60^{\circ}$, and (e) $90^{\circ}$.

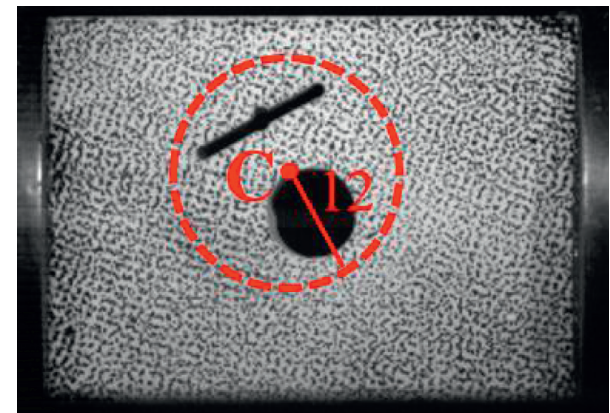

Figure 9: Diagrammatic sketch of the selected failure zone in specimen U-45.

the rock specimens, and this part of energy has the main contribution for the failure of rock and also the new fractures in the specimen. Figure 11 plots the relationship between the absorption energy $E_{\mathrm{A}}$ and the flaw inclination angle. It is obvious that $E_{\mathrm{A}}$ first decreases then rises gradually with the inclination angle increasing, and it reaches the lowest value at $45^{\circ}$. This is because the precracked specimens with a flaw of $45^{\circ}$ absorb only a relatively small amount of energy, fractures generate inside the specimens, and failure occurs, while other types of specimens require more energy to break. The variation trend of absorption energy is similar to that of combined strength of the specimens, as shown in Figure 6.

4.4. Rock Fragmentation Size Analysis. Macrofractures are formed in the rock specimens under coupled static-dynamic loading. This behavior inevitably leads to the fragmentation and energy dissipation in the rock failure process. The distribution characteristics of rock fragmentation size can

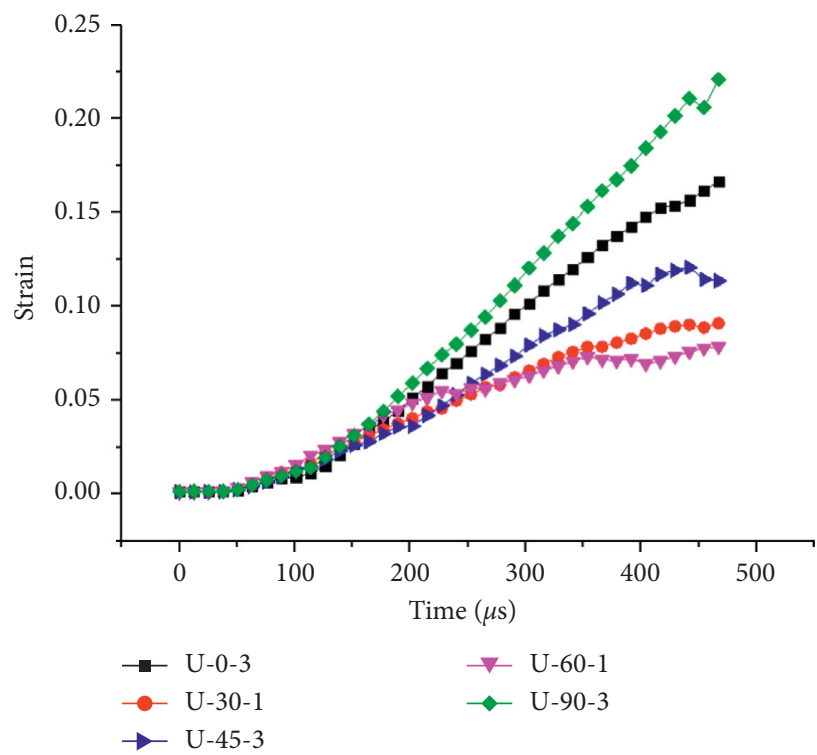

FIGURE 10: Average strain-time curves of the main failure zones of five typical specimens.

reflect the extent of deformation and failure behavior of rocks. The greater the damage degree of rock specimen will result in better dispersion and more homogenous diameter of rock fragment. Figure 12(a) shows the fragment of the granite specimen after impact load. It is worth noting that in order to make the results of size analysis more reasonable, all fragments of the specimens in the same inclination angle are mixed together. Then, the split desktop, a rock fragmentation size measurement software, is used to analyze the size data in each group. The processed picture of Group U-30 is 
TABLE 7: Energy properties of flawed granite specimens under SHPB tests.

\begin{tabular}{lcccc}
\hline Specimen no. & Incident energy $(\mathrm{J})$ & Reflected energy $(\mathrm{J})$ & Transmitted energy $(\mathrm{J})$ & Absorbed energy $(\mathrm{J})$ \\
\hline $\mathrm{C}-0$ & 59.30 & 22.62 & 11.27 & 25.41 \\
$\mathrm{U}-0$ & 56.59 & 21.01 & 9.90 & 25.68 \\
$\mathrm{U}-30$ & 60.66 & 32.52 & 5.20 & 22.95 \\
$\mathrm{U}-45$ & 53.43 & 30.71 & 4.25 & 18.46 \\
$\mathrm{U}-60$ & 62.55 & 39.33 & 4.26 & 18.97 \\
U-90 & 61.59 & 31.59 & 6.25 & 23.75 \\
\hline
\end{tabular}

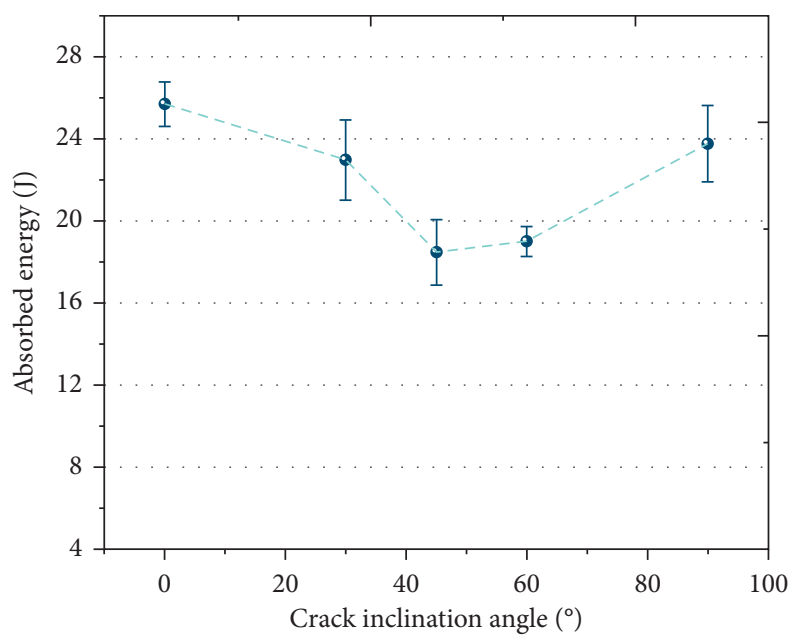

- Average data

Figure 11: The relationship between the absorption energy $E_{A}$ and the flaw inclination angle.

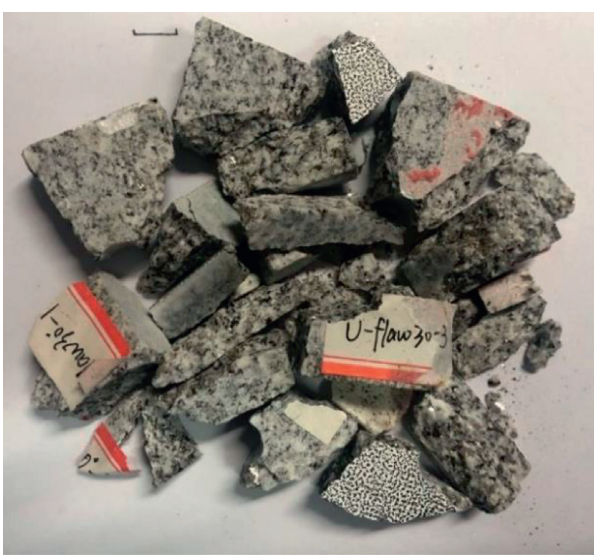

(a)

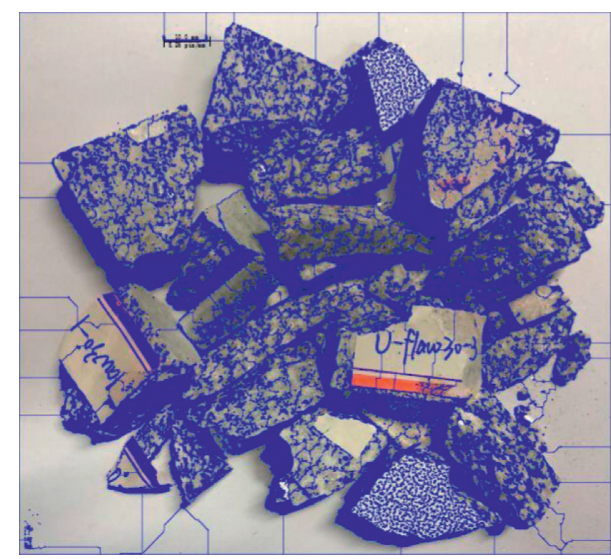

(b)

FIGURE 12: Rock fragmentation pictures of Group U-30: (a) rock fragments and (b) processed picture by split desktop software.

shown in Figure 12(b), and all rock fragmentation size data are summarized in Table 8 . It lists the percentage of rock fragment in each interval, as well as the average size and top size in each group. Almost all the fragment size is less than $5.08 \mathrm{~cm}$, except for some fragment in Group U-90, which accounts for $5.87 \%$. Furthermore, it is clear that with the increase of inclination angle, the average size and top size of the specimens show a trend of decreasing firstly and then increasing, and they both reach the lowest at the angle of $45^{\circ}$, which is consistent with the variation trend of combined strength and absorption energy.

Figure 13 shows the fragment size distribution of granite specimens with different angles after crush. It reflects the fragmentation degree of the specimens. It can be seen that when the crack inclination angle is $45^{\circ}$, the specimens are broken into smaller particle sizes with homogenous size distribution. The specimens with an angle of $30^{\circ}$ rank second; nevertheless, the amount of rock fragment with the size 
TABLE 8: Statistical parameters of rock fragments.

\begin{tabular}{lcccccc}
\hline Size $(\mathrm{cm})$ & C-0 & 0 & 30 & 45 & 60 & 90 \\
& \multicolumn{5}{c}{ Percentage of different } & size $(\%)$ \\
\hline$<0.20$ & 27.28 & 23.37 & 35.59 & 24.29 & 24.23 & 25.91 \\
$0.20 \sim 0.48$ & 3.50 & 9.32 & 5.48 & 13.97 & 2.54 & 9.77 \\
$0.48 \sim 0.64$ & 1.60 & 1.59 & 2.32 & 6.30 & 1.62 & 4.04 \\
$0.64 \sim 0.97$ & 3.91 & 3.38 & 5.47 & 10.53 & 4.04 & 4.84 \\
$0.97 \sim 1.27$ & 5.98 & 4.41 & 7.63 & 7.74 & 6.38 & 3.04 \\
$1.27 \sim 1.91$ & 16.73 & 15.77 & 18.17 & 17.22 & 21.41 & 7.16 \\
$1.97 \sim 2.54$ & 16.71 & 18.66 & 14.80 & 12.45 & 21.95 & 9.01 \\
$2.54 \sim 5.08$ & 24.29 & 23.50 & 10.54 & 7.50 & 17.83 & 30.36 \\
$5.08 \sim 10.16$ & 0.00 & 0.00 & 0.00 & 0.00 & 0.00 & 5.87 \\
Average size & 3.42 & 3.40 & 2.43 & 2.23 & 3.31 & 4.15 \\
Top size & 4.42 & 4.24 & 3.38 & 3.23 & 3.66 & 5.94 \\
\hline
\end{tabular}

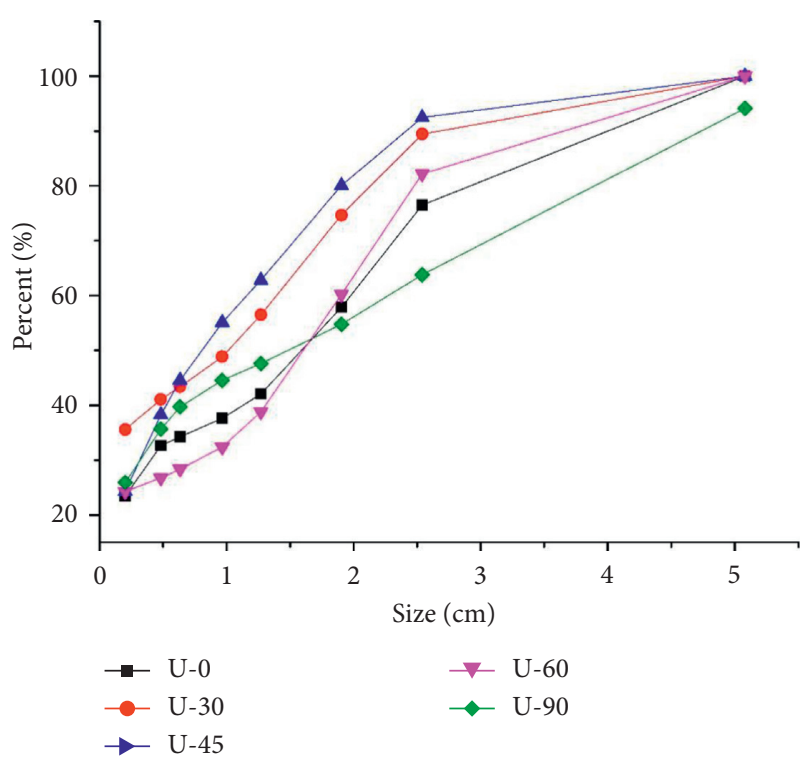

FIgURE 13: The fragmentation size distribution of granite specimens with different flaw angles.

less than $0.5 \mathrm{~cm}$ is the maximum at this angle. The specimens with flaw angles of $0^{\circ}$ and $60^{\circ}$ have less small size fragments but more large size fragments. The uniformity of fragment size distribution for the specimen with $90^{\circ}$ flaw angle is the worst.

\section{Conclusions}

A series of impact tests are conducted on granite specimens with combined hole and crack flaws. The DIC technique is used to monitor the surface strain evolution and failure behavior of the specimens. The conclusions are drawn as follows:

(1) Mechanical properties of granite with crack-hole flaws are susceptible to the crack inclination angles. The combined strength and the peak strain of the specimens both decrease first and then increase with the flaw inclination angle increasing, and both of them reach the lowest value at the angle of $45^{\circ}$.

(2) The influence of flaw inclination angle on the deformation of the specimen reflects the fracturing behavior. Two crack tips $(A, B)$, and the top and bottom of the internal hole $(D, E)$ are the main stress concentration zones, and their local maximum strain is basically more than 0.5 at postpeak stage.

(3) The crack coalescence modes between combined flaws are summarized, i.e., regional failure, monotype fracture, and mixed mode fractures. Tensile fractures tend to occur at the crack tip, while shear fractures usually emerge at the top and bottom of the hole and dominate the ultimate rock failure process under dynamic impact loading.

(4) The absorption energy $E_{\mathrm{A}}$ first increases and then decreases with the flaw inclination angle. Furthermore, the size distribution of rock fragments is analyzed. The specimens with crack of $45^{\circ}$ are broken relatively evenly with homogenous particle size distribution. The characteristics of absorption energy and size distribution are consistent with the variation trend of combined strength.

\section{Data Availability}

The relevant data could be found in the manuscript.

\section{Conflicts of Interest}

The authors declare that they have no conflicts of interest.

\section{Acknowledgments}

The authors would like to acknowledge the financial support from the Outstanding Youth Science Foundations of Hunan Province of China (no. 2019JJ20028), the Key Projects of the National Natural Science Foundation of China (no. 41630642), and the Graduate Student Research and Innovation Fund of Central South University (no. 1053320183421).

\section{References}

[1] E. Hoek and C. D. Martin, "Fracture initiation and propagation in intact rock-a review," Journal of Rock Mechanics and Geotechnical Engineering, vol. 6, no. 4, pp. 287-300, 2014.

[2] F. Feng, X. B. Li, J. Rostami, D. X. Peng, D. Y. Li, and K. Du, "Numerical investigation of hard rock strength and fracturing under polyaxial compression based on Mogi-Coulomb failure criterion," International Journal of Geomechanics, vol. 19, no. 4, Article ID 04019005, 2019.

[3] C. P. Zhang, P. G. Ranjith, and Z. Y. Zhang, "Experimental study of fracturing behaviour in ultralow permeability formations: a comparison between $\mathrm{CO}_{2}$ and water fracturing," Engineering Fracture Mechanics, vol. 217, Article ID 106541, 2019.

[4] F. Dai, S. Huang, K. Xia, and Z. Tan, "Some fundamental issues in dynamic compression and tension tests of rocks using split Hopkinson pressure bar," Rock Mechanics and Rock Engineering, vol. 43, no. 6, pp. 657-666, 2010.

[5] Y. L. Gui, J. L. Shang, J. J. Ma, and Z. Y. Zhao, "Numerical study of the circular opening effect on mechanical behaviour of rock under confinement," Journal of Rock Mechanics and Geotechnical Engineering, vol. 11, no. 6, pp. 1201-1210, 2019. 
[6] X.-R. Liu, S.-Q. Yang, Y.-H. Huang, and J.-L. Cheng, "Experimental study on the strength and fracture mechanism of sandstone containing elliptical holes and fissures under uniaxial compression," Engineering Fracture Mechanics, vol. 205, pp. 205-217, 2019.

[7] W. Zeng, S.-Q. Yang, and W.-L. Tian, "Experimental and numerical investigation of brittle sandstone specimens containing different shapes of holes under uniaxial compression," Engineering Fracture Mechanics, vol. 200, pp. 430-450, 2018.

[8] Q. Zhang, X. Wang, L. G. Tian, and D. M. Huang, "Analysis of mechanical and acoustic emission characteristics of rock materials with double-hole defects based on particle flow code," Shock and Vibration, Article ID 7065029, 11 pages, 2018.

[9] Q.-S. Bai, S.-H. Tu, and C. Zhang, "DEM investigation of the fracture mechanism of rock disc containing hole(s) and its influence on tensile strength," Theoretical and Applied Fracture Mechanics, vol. 86, pp. 197-216, 2016.

[10] Y. Liu, F. Dai, L. Dong, N. Xu, and P. Feng, "Experimental investigation on the fatigue mechanical properties of intermittently jointed rock models under cyclic uniaxial compression with different loading parameters," Rock Mechanics and Rock Engineering, vol. 51, no. 1, pp. 47-68, 2018.

[11] Y. Gao, X.-T. Feng, Z. Wang, and X. Zhang, "Strength and failure characteristics of jointed marble under true triaxial compression," Bulletin of Engineering Geology and the Environment, vol. 79, no. 2, pp. 891-905, 2020.

[12] S.-Q. Yang, X.-R. Liu, and H.-W. Jing, "Experimental investigation on fracture coalescence behavior of red sandstone containing two unparallel fissures under uniaxial compression," International Journal of Rock Mechanics and Mining Sciences, vol. 63, pp. 82-92, 2013.

[13] L. N. Y. Wong and H. H. Einstein, "Systematic evaluation of cracking behavior in specimens containing single flaws under uniaxial compression," International Journal of Rock Mechanics and Mining Sciences, vol. 46, no. 2, pp. 239-249, 2009.

[14] D. Huang, D. Gu, C. Yang, R. Huang, and G. Fu, "Investigation on mechanical behaviors of sandstone with two preexisting flaws under triaxial compression," Rock Mechanics and Rock Engineering, vol. 49, no. 2, pp. 375-399, 2016.

[15] J. Wu, M. Feng, B. Yu, and G. Han, "The length of pre-existing fissures effects on the mechanical properties of cracked red sandstone and strength design in engineering," Ultrasonics, vol. 82, pp. 188-199, 2018.

[16] S.-q. Yang, H.-w. Jing, and T. Xu, "Mechanical behavior and failure analysis of brittle sandstone specimens containing combined flaws under uniaxial compression," Journal of Central South University, vol. 21, no. 5, pp. 2059-2073, 2014.

[17] T. Liu, B. Lin, W. Yang, Q. Zou, J. Kong, and F. Yan, “Cracking process and stress field evolution in specimen containing combined flaw under uniaxial compression," Rock Mechanics and Rock Engineering, vol. 49, no. 8, pp. 3095-3113, 2016.

[18] Q. Yin, H. Jing, and H. Su, "Investigation on mechanical behavior and crack coalescence of sandstone specimens containing fissure-hole combined flaws under uniaxial compression," Geosciences Journal, vol. 22, no. 5, pp. 825-842, 2018.

[19] C. Zou and L. N. Y. Wong, "Experimental studies on cracking processes and failure in marble under dynamic loading," Engineering Geology, vol. 173, pp. 19-23, 2014.

[20] C. Zou, L. N. Y. Wong, J. J. Loo, and B. S. Gan, "Different mechanical and cracking behaviors of single-flawed brittle gypsum specimens under dynamic and quasi-static loadings," Engineering Geology, vol. 201, pp. 71-84, 2016.
[21] X. B. Li, T. Zhou, and D. Y. Li, "Dynamic strength and fracturing behavior of single-flawed prismatic marble specimens under impact loading with a split-hopkinson pressure bar," Rock Mechanics and Rock Engineering, vol. 50, no. 1, pp. 29-44, 2017.

[22] Z. Jing, W. Dong, and W. L. Chang, Experimental Study on Post-peak Mechanical Properties of Hard Rocks under Combined Static and Dynamic Loading, Sichuan University, Chengdu, China, 2015.

[23] P. Feng, F. Dai, Y. Liu, and H.-b. Du, "Mechanical behaviors of rock-like specimens with two non-coplanar fissures subjected to coupled static-dynamic loads," Engineering Fracture Mechanics, vol. 199, pp. 692-704, 2018.

[24] W. C. Zhu, Y. Bai, X. B. Li, and L. L. Niu, "Numerical simulation on rock failure under combined static and dynamic loading during SHPB tests," International Journal of Impact Engineering, vol. 49, pp. 142-157, 2012.

[25] K. Bharadwaj, A. Sheidaei, A. Afshar, and J. Baqersad, "Fullfield strain prediction using mode shapes measured with digital image correlation," Measurement, vol. 139, pp. 326333, 2019.

[26] J. Baqersad, J. Carr, T. Lundstrom, C. Niezrecki, P. Avitabile, and M. Slattery, "Dynamic characteristics of a wind turbine blade using 3D digital image correlation," International Society Optics and Photonics, vol. 8348, pp. 83482I-83489I, 2012.

[27] D. Li, L. N. Y. Wong, G. Liu, and X. Zhang, "Influence of water content and anisotropy on the strength and deformability of low porosity meta-sedimentary rocks under triaxial compression," Engineering Geology, vol. 126, pp. 46-66, 2012.

[28] K. Muniandy, Z. Mohamad Ariff, and A. Abu Bakar, "Digital image correlation utilization in measuring displacement and strain during plastic film blowing process: a feasibility study," Measurement, vol. 136, pp. 487-500, 2019.

[29] G. L. Golewski, "Measurement of fracture mechanics parameters of concrete containing fly ash thanks to use of Digital Image Correlation (DIC) method," Measurement, vol. 135, pp. 96-105, 2019.

[30] W. W. Ji, P. Z. Pan, S. T. Miao, F. S. Su, and M. P. Du, "Fracture characteristics of two types of rocks based on digital image correlation," Rock and Soil Mechanics, vol. 37, no. 8, pp. 2299-2305, 2016.

[31] X. Li, Z. Zhou, T.-S. Lok, L. Hong, and T. Yin, "Innovative testing technique of rock subjected to coupled static and dynamic loads," International Journal of Rock Mechanics and Mining Sciences, vol. 45, no. 5, pp. 739-748, 2008.

[32] W.-W. Ji, P.-Z. Pan, Q. Lin, X.-T. Feng, and M.-P. Du, "Do disk-type specimens generate a mode II fracture without confinement?" International Journal of Rock Mechanics and Mining Sciences, vol. 87, pp. 48-54, 2016.

[33] D. Y. Li, Z. Y. Han, X. L. Sun, T. Zhou, and X. B. Li, "Dynamic mechanical properties and fracturing behavior of marble specimens containing single and double flaws in SHPB tests," Rock Mechanics Rock Engineering, vol. 52, no. 6, pp. 16232164, 2019.

[34] H. W. Zhou, Z. H. Wang, C. S. Wang, and J. F. Liu, "On acoustic emission and post-peak energy evolution in beishan granite under cyclic loading," Rock Mechanics and Rock Engineering, vol. 52, no. 1, pp. 283-288, 2019.

[35] W. G. P. Kumari, P. G. Ranjith, M. S. A. Perera et al., "Hydraulic fracturing under high temperature and pressure conditions with micro CT applications: geothermal energy from hot dry rocks," Fuel, vol. 230, pp. 138-154, 2018.

[36] X. P. Zhou, Y. X. Zhang, and Q. L. Ha, "Real-time computerized tomography (CT) experiments on limestone 
damage evolution during unloading," Theoretical and Applied Fracture Mechanics, vol. 50, no. 1, pp. 49-56, 2008.

[37] M. M. Kou, X. R. Liu, S. D. Tang, and Y. T. Wang, "3-D X-ray computed tomography on failure characteristics of rock-like materials under coupled hydro-mechanical loading," Theoretical and Applied Fracture Mechanics, vol. 104, Article ID 102396, 2019.

[38] G. Li, X. F. Cheng, H. Pu, and C. A. Tang, "Damage smear method for rock failure process analysis," Journal of Rock Mechanics and Geotechnical Engineering, vol. 11, no. 6, pp. 1151-1165, 2019.

[39] Y. Q. Zhou, Q. Sheng, N. N. Li, and X. D. Fu, "Numerical investigation of the deformation properties of rock materials subjected to cyclic compression by the finite element method," Soil Dynamics and Earthquake Engineering, vol. 126, Article ID 105795, 2019.

[40] Y. Ju, Y. L. Wang, C. S. Su, D. S. Zhang, and Z. Y. Ren, "Numerical analysis of the dynamic evolution of mininginduced stresses and fractures in multilayered rock strata using continuum-based discrete element methods," International Journal of Rock Mechanics and Mining Sciences, vol. 113, no. 1, pp. 91-210, 2019.

[41] C. A. Tang and S. Tang, "Applications of rock failure process analysis (RFPA) method," Journal of Rock Mechanics and Geotechnical Engineering, vol. 3, no. 4, pp. 352-372, 2011.

[42] W. Zhao, R. Huang, and M. Yan, "Study on the deformation and failure modes of rock mass containing concentrated parallel joints with different spacing and number based on smooth joint model in PFC," Arabian Journal of Geosciences, vol. 8, no. 10, pp. 7887-7897, 2015.

[43] M. Tao, A. Ma, W. Cao, X. Li, and F. Gong, "Dynamic response of pre-stressed rock with a circular cavity subject to transient loading," International Journal of Rock Mechanics and Mining Sciences, vol. 99, pp. 1-8, 2017.

[44] D. Y. Li, P. Xiao, Z. Y. Han, and Q. Q. Zhu, "Mechanical and failure properties of rocks with a cavity under coupled static and dynamic loads," Engineering Fracture Mechanics, vol. 225, Article ID 106195, 2020.

[45] Q. Zhu, D. Li, Z. Han, X. Li, and Z. Zhou, "Mechanical properties and fracture evolution of sandstone specimens containing different inclusions under uniaxial compression," International Journal of Rock Mechanics and Mining Sciences, vol. 115, pp. 33-47, 2019.

[46] Correlated Solutions Vic-2D User's Manual, 4th edition, SC, West Columbia, 2006.

[47] B. Pan, A. Asundi, H. M. Xie, and J. X. Gao, "Digital image correlation using iterative least squares and pointwise least squares for displacement field and strain field measurements," Optics and Lasers in Engineering, vol. 47, no. 7-8, pp. 865-874, 2009.

[48] Z. Y. Han, D. Y. Li, T. Zhou, Q. Q. Zhu, and P. G. Ranjith, "Experimental study of stress wave propagation and energy characteristics across rock specimens containing cemented mortar joint with various thicknesses," International Journal of Rock Mechanics and Mining Sciences, vol. 131, Article ID 104352, 2020.

[49] C. Zou, L. N. Y. Wong, J. J. Loo, and B. S. Gan, "Different mechanical and cracking behaviors of single-flawed brittle gypsum specimens under dynamic and quasi-static loadings," Engineering Geology, vol. 201, pp. 71-84, 2016.

[50] Q. B. Zhang and J. Zhao, "Determination of mechanical properties and full-field strain measurements of rock material under dynamic loads," International Journal of Rock Mechanics and Mining Sciences, vol. 60, no. 8, pp. 423-439, 2013.
[51] S. P. Morgan, C. A. Johnson, and H. H. Einstein, "Cracking processes in Barre granite: fracture process zones and crack coalescence," International Journal of Fracture, vol. 180, no. 2, pp. 177-204, 2013.

[52] J. J. F. Bonnen and T. H. Topper, "Threshold crack growth behavior of shear and tensile cracks," International Journal of Fatigue, vol. 42, pp. 122-130, 2012.

[53] M. G. Tarantino, S. Beretta, S. Foletti, and I. Papadopoulos, "Experiments under pure shear and rolling contact fatigue conditions: competition between tensile and shear mode crack growth," International Journal of Fatigue, vol. 46, pp. 67-80, 2013.

[54] S. Liu, Y. J. Chao, and X. Zhu, "Tensile-shear transition in mixed mode I/III fracture," International Journal of Solids and Structures, vol. 41, no. 22-23, pp. 6147-6172, 2004. 